\title{
Study on the Influence of Different Carbon Sources on Nitrogen and Phosphorus Removal with Micro-pressure swirl Reactor
}

\author{
Xi Tian ${ }^{1,2}$, Xuejiao Li ${ }^{1,2}$, Yanhong Lv ${ }^{1,2}$, Penghui Dong ${ }^{1,2}$, Longfei Yang ${ }^{1}$, Luyao Xue ${ }^{1}$ and Dejun Bian ${ }^{1,2, *}$ \\ ${ }^{1}$ Changchun Institute of Technology, Changchun, Jilin, 130012, China \\ ${ }^{2}$ Jilin Provincial Key Laboratory of Municipal Wastewater Treatment, Changchun, Jilin, 130012, China
}

\begin{abstract}
To explore the suitable external carbon sources for Micro-pressure swirl Reactor (MPR), the experiment was run in parallel through two MPRs, using starch and glucose as carbon sources respectively. Research indicated that under the experimental operating conditions, using starch as the carbon source could more effectively promote the biological denitrification of the MPR system. Due to the structural characteristics of MPR and the slow degradation of starch, the demand for carbon source for denitrification was ensured during the operation cycle, so that the system obtained a better denitrification effect. The test results provided reference for the selection of the external carbon source of the MPR process.
\end{abstract}

\section{Introduction}

At present, biological nitrogen and phosphorus removal is the most economical and effective means to control water pollution [1]. To effectively remove nitrogen and phosphorus and adapt to various water quality, researchers have designed a variety of sewage biological nitrogen and phosphorus removal processes, and the micro-pressure swirl reactor (MPR) was one of them. The MPR was combined the ordinary activated sludge method and the mass transfer theory of sludge mixed liquid. By simply improving the traditional biochemical aeration tank, the reactor had a unique aeration method and a circulating flow state of activated sludge. Controlling the amount of aeration reasonably, three different dissolved oxygen environments (anaerobic, anoxic and aerobic) could exist in a single aeration tank at the same time. The feature made it more able for MPR to achieve simultaneous nitrogen and phosphorus removal from sewage [2].

Meanwhile, in the biological sewage treatment process, the carbon source is the key to the denitrification and phosphorus removal. The carbon source not only provides the energy needed for the growth of heterogeneous bacteria, but also is an important carrier of electron transfer and energy supply in the process of biological nitrogen and phosphorus removal [3]. Most urban sewage treatment plants in China face low carbon-nitrogen ratios and cannot meet the normal biological carbon source requirements for nitrogen and phosphorus removal. While the sewage discharge standards continuous improvement, insufficient carbon sources have become a limiting factor for the further improvement of the capacity and efficiency of nitrogen and phosphorus removal. Therefore, most urban sewage treatment plants need to add external carbon source to improve the nitrogen and phosphorus removal efficiency [4]. Because starch and glucose have better availability and economy, they have been widely used as external carbon sources in urban sewage treatment processes.

In previous research, MPR had excellent performance in the treatment of low-temperature sewage, high-concentration wastewater and energy saving and consumption reduction, but the influence of different carbon sources on its nitrogen and phosphorus removal was still not clear $[2,5,6,7]$. This study investigated the effects of different carbon sources on MPR biological nitrogen and phosphorus removal by adding starch and glucose to the two MPR systems, aimed to provide references for the selection of other carbon sources and the practical application for MPR process.

\section{MATERIALS AND METHODS}

\subsection{Experimental setup}

The test device is shown in Fig. 1. The reactor could be divided into two parts, the main reaction part and the water level lifting part. By setting an aeration device along one side of the bottom, air bubbles could be used to drive the liquid flow, so that the mixed liquid in the reactor could be powered and circulated. Since sewage and air bubbles were mainly in contact with the aeration side, under proper aeration amount, the dissolved oxygen concentration could be gradually reduced from the outside to the center [2]. This study used two identical MPRs to run in parallel. Both reactors were made of plexiglass plates. The main reaction zone was a cylinder with a diameter of $300 \mathrm{~mm}$ and a width of $300 \mathrm{~mm}$. The water level lifting part was $300 * 50 * 100 \mathrm{~mm}(\mathrm{~L} * \mathrm{~B} * \mathrm{H})$,

*Corresponding author: ccgcxybiandj@163.com 
and the supporting structure was $310 * 300 * 200 \mathrm{~mm}(\mathrm{~L} * \mathrm{~B} * \mathrm{H})$, the effective volume of the reactors was $12 \mathrm{~L}$. A sampling point was set at the central point of the main reaction part, and a vent pipe was set at the bottom for venting and used to discharge sludge.

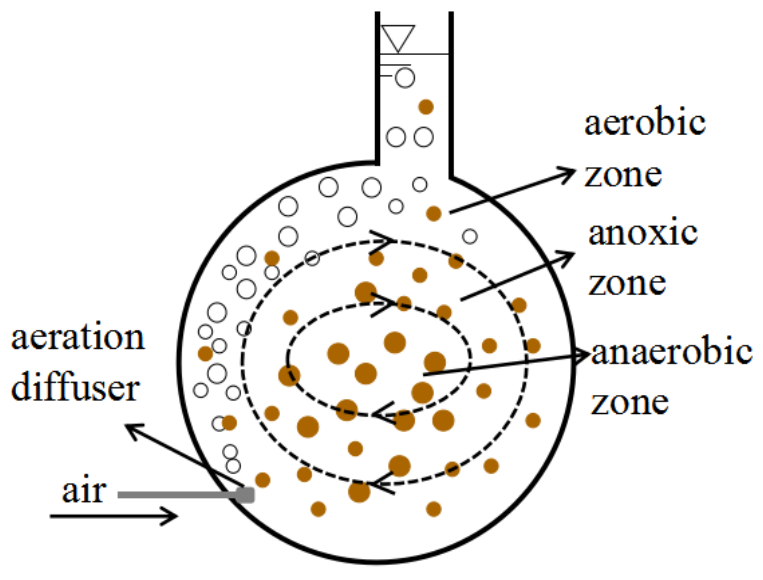

Fig. 1. MPR structure diagram

\subsection{Operating conditions and water quality}

Both MPRs were run in sequential batch mode, running two cycles per day. Specifically, it consisted of $5 \mathrm{~min}$ of water intake, $450 \mathrm{~min}$ of aeration, $240 \mathrm{~min}$ of static sedimentation, $5 \mathrm{~min}$ of drainage, and $20 \mathrm{~min}$ of inactivity. The drainage volume per cycle was $6 \mathrm{~L}$, and the drainage ratio was $50 \%$. An air compressor (ACO-12, Sun Sun, China) was used for aeration, and an air rotor flow meter (LZB-DK600-4F, Cheng feng, China) was used to control the aeration volume to $1.0 \mathrm{~L} / \mathrm{min}$. $400 \mathrm{~mL}$ of the mixed solution was discharged before the end of aeration everyday, and the sludge retention time (SRT) was controlled at about $30 \mathrm{~d}$. The experiment used artificial water distribution. The carbon sources of the two reactors were configured by starch $\left[\left(\mathrm{C}_{6} \mathrm{H}_{12} \mathrm{O}_{5}\right) \mathrm{n}\right]$ and glucose $\left(\mathrm{C}_{6} \mathrm{H}_{12} \mathrm{O}_{6}\right)$ respectively. Ammonium chloride $\left(\mathrm{NH}_{4} \mathrm{Cl}\right)$ provided nitrogen source, potassium dihydrogen phosphate $\left(\mathrm{KH}_{2} \mathrm{PO}_{4}\right)$ provided phosphorus source and sodium hydrogen $\left(\mathrm{NaHCO}_{3}\right)$ was used to adjust the $\mathrm{pH}$. During the test, the influent COD concentration was $465 \sim 561.3 \mathrm{mg} / \mathrm{L}$, the TN concentration was $30.53 \sim 40.82 \mathrm{mg} / \mathrm{L}$, the $\mathrm{NH}_{4}{ }^{+}-\mathrm{N}$ concentration was $30.53 \sim 40.82 \mathrm{mg} / \mathrm{L}$, the TP concentration was $3.016 \sim 3.888 \mathrm{mg} / \mathrm{L}$, and the influent $\mathrm{pH}$ was $7.5 \sim 8.5$.

\subsection{Index detection}

During the test, a routine index test was carried out every two days. Among them, COD, TN, $\mathrm{NH}_{4}{ }^{+}-\mathrm{N}$, TP, MLSS were measured with reference to the standard method [8]; the $\mathrm{pH}$ value was measured with a acidity meter (PHSJ$4 \mathrm{~A}$, Leici, China); $\mathrm{NO}_{2}{ }^{-}-\mathrm{N}$ and $\mathrm{NO}_{3}{ }^{-}-\mathrm{N}$ were detected by ion chromatography.

\section{Results and discussion}

\subsection{The impact of different carbon sources on the MPR wastewater treatment effect}

\subsubsection{The effect of different carbon sources on the COD removal of MPR}

Fig. 2(a) shows the changes in the COD concentration and removal rate of the inlet and outlet water during the test of the two MPR systems. The COD concentration of MPR feed water with starch and glucose as carbon sources were $508.7 \sim 588.4$ and $465 \sim 529.7 \mathrm{mg} / \mathrm{L}$, and the average COD removal rates of the two reactors were $95.08 \%$ and $93.67 \%$, respectively. The test results showed that different carbon sources had little effect on the COD removal efficiency of the MPR system. During the test, the COD effluent concentration of the two was better than the first-level A standard.

To further explore the influence mechanism of different carbon sources on the denitrification and phosphorus removal of the MPR system, the change of COD with aeration time in a typical cycle was tested. As Fig. 2(b) shows, the COD concentration change rules of the two carbon sources during the cycle were quite different. At the time of aeration for $5 \mathrm{~min}$, the COD concentration of the MPR system with starch and glucose as carbon sources decreased from 559.9 and $544.3 \mathrm{mg} / \mathrm{L}$ to 180.6 and $57.19 \mathrm{mg} / \mathrm{L}$, respectively, while the COD concentration of the former remained high until the end of the aeration. At the end of the aeration, the COD concentrations of the two were 45.15 and 18.16 $\mathrm{mg} / \mathrm{L}$, respectively. Obviously, in the COD degradation process, the degradation rate of glucose was faster. After $65 \mathrm{~min}$ of aeration, the concentration of water-soluble COD in the MPR system with glucose as the carbon source was lower than $30 \mathrm{mg} / \mathrm{L}$, which led to the lack of carbon sources for denitrification in the system. Due to the low COD concentration and low DO consumption, the overall DO concentration of the system was higher, thereby inhibiting the activity of denitrifying bacteria. These eventually led to the poor denitrification effect of the MPR system with glucose as the carbon source. On the contrary, the MPR system with starch as the carbon source has always had a relatively high COD concentration during the aeration period, which promoted a relatively low DO concentration in the system. Combined with the structural characteristics of MPR, its dissolved oxygen was more likely to form partitions, thereby avoiding competition between functional flora and conducive to system denitrification. 


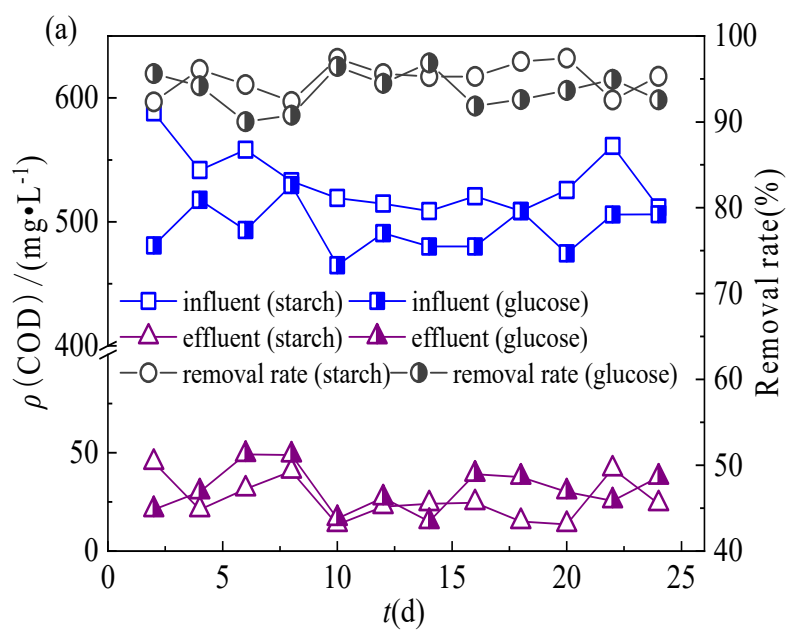

(1)

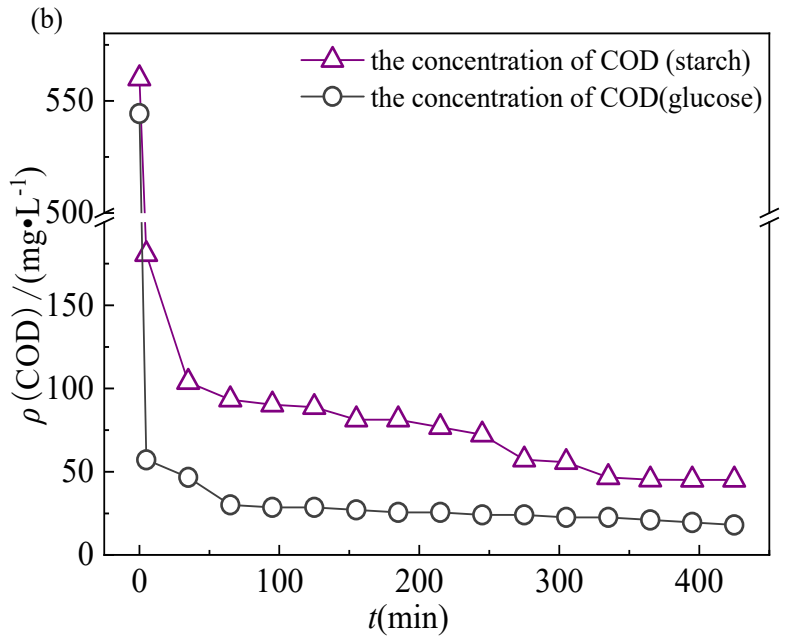

Fig. 2. COD removal effect of MPR under different carbon sources

\subsubsection{The influence of different carbon sources on MPR denitrification}

Fig. 3 and 4 show the changes in $\mathrm{NH}_{4}{ }^{+}-\mathrm{N}$ and $\mathrm{TN}$ inlet and outlet water concentration and removal rate during the test of the two MPR systems. From Fig. 3, the $\mathrm{NH}_{4}{ }^{+}-$ $\mathrm{N}$ concentration of MPR influent with starch and glucose as carbon sources were 27.35 33.15 and 27.64 32.9 $\mathrm{mg} / \mathrm{L}$, and the average effluent concentration was 0.74 and $0.72 \mathrm{mg} / \mathrm{L}$, respectively. The rates were all above $97 \%$. It meant that the reactor had sufficient DO supply and the nitrification performance of the two reactors was good. The nitrification reaction was not a decisive step that limited the denitrification effect of the two reactors. From Figure 4, the final denitrification effect between the two was quite different. During the experiment, the influent TN concentration of the two was 30.53 39.16 and $30.8 \sim 40.82 \mathrm{mg} / \mathrm{L}$, the average concentration was 2.17 and $6.94 \mathrm{mg} / \mathrm{L}$, and the average removal rate was $93.71 \%$ and $80.63 \%$, respectively. The difference of the average removal rate of $\mathrm{TN}$ between the two was $13.08 \%$. The carbon source had a greater impact on the denitrification in the biological denitrification process of the MPR system. By comparing the two carbon sources of glucose and starch, it could be found that starch was a macromolecular organic matter. In the sewage treatment process, the degradation process of macromolecular organic matter was relatively slow [9]. At the beginning of the cycle reaction, due to the rapid consumption of glucose, the carbon source for denitrification in the later stage of the reaction was insufficient, which made the denitrification effect poor. In addition, the structural characteristic of MPR was also an important reason for this difference. With the consumption of organic matter, the ordinary aeration tank was in aerobic state in the later stage of the reaction. In MPR, due to the single-sided aeration, the air bubbles only contact the sewage at the aeration side, which made the DO increase relatively slowly in the center area of the reactor. This feature was conducive to the MPR system to use of internal sources for denitrification. The more difficult-to-degrade starch characteristics enable more carbon sources to be stored by microorganisms in the initial stage of the reaction, so that the denitrification effect of the system was further improved.

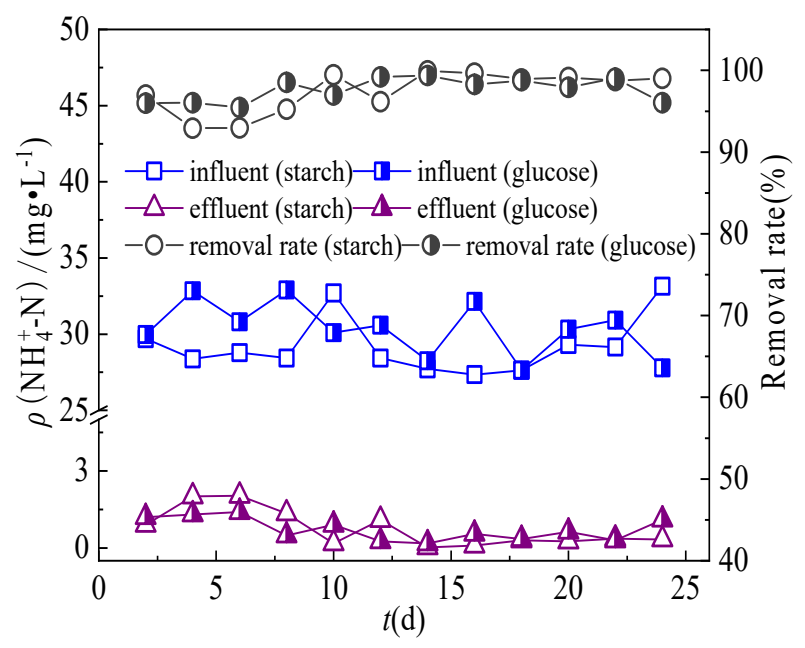

Fig. 3. $\mathrm{NH}_{4}{ }^{+}-\mathrm{N}$ removal effect of MPR under different carbon sources

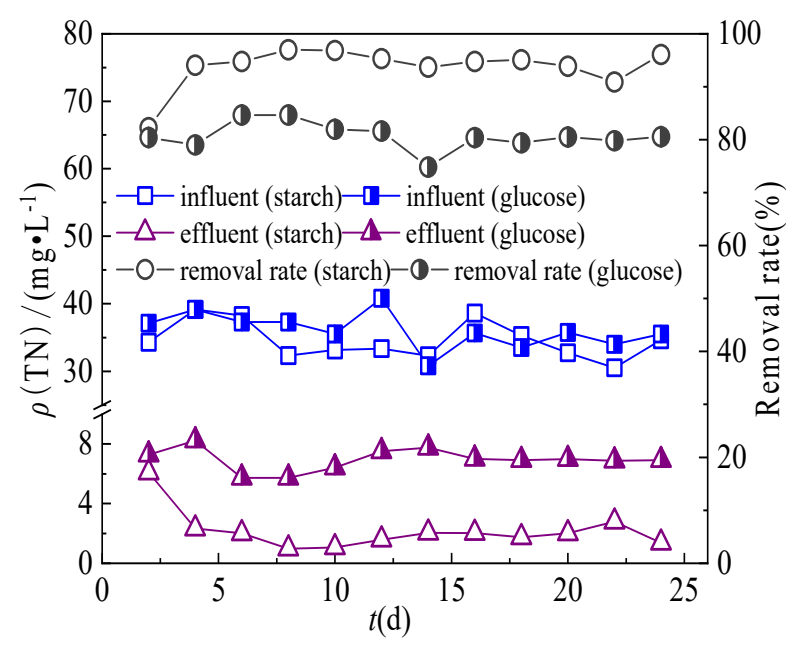

Fig. 4. TN removal effect of MPR under different carbon sources 


\subsubsection{The influence of different carbon sources on MPR phosphorus removal}

Fig. 5 shows the changes in the TP inlet and outlet water concentration and its removal efficiency during the test of the two MPR systems. The MPR influent TP concentration with starch and glucose as carbon sources was $3.016 \sim 3.888 \mathrm{mg} / \mathrm{L}$, the average effluent concentration of the two were 0.33 and $0.059 \mathrm{mg} / \mathrm{L}$, and the average removal rate were $90.48 \%$ and $98.27 \%$ respectively. It could be seen from the results that when the influent carbon source was glucose, the phosphorus removal effect of the MPR system was better, which was the opposite of nitrogen removal. The removal of phosphorus in the system mainly relied on the excessive phosphorus absorption of phosphorus accumulating bacteria, which absorbed phosphorus from the liquid phase into the solid phase, and achieved the purpose of phosphorus removal through sludge discharge. The anaerobic release of phosphorus was the key to complete this process. Studies have shown that phosphorus accumulating bacteria could only fully release phosphorus under anaerobic conditions before they could fully absorb phosphorus in the aerobic stage. Similarly, it was not difficult to find from the analysis of the degradation process of the carbon source, because glucose was a single-molecule organic matter. Under the same conditions, glucose was more able to be converted into the precursor substance of $\mathrm{PHA} / \mathrm{PHB}$ at the beginning of the cycle. This was beneficial to the anaerobic release of phosphorus by phosphorus accumulating bacteria, and ultimately made the phosphorus removal effect better than the MPR system using starch as a carbon source.

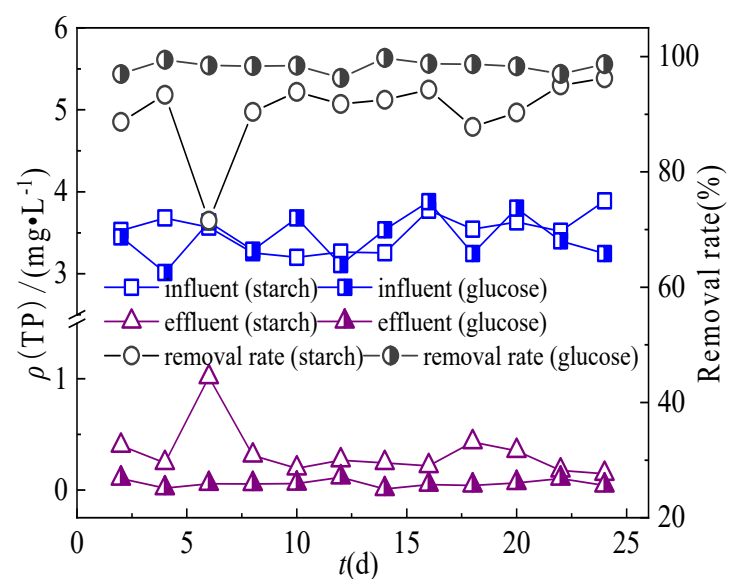

Fig 5. TP removal effect of MPR under different carbon sources

\section{Conclusion}

To explore the external carbon source suitable for MPR, the experiment was run in parallel by two MPRs, and a single carbon source was added separately to investigate the effect of starch and glucose on MPR biological nitrogen and phosphorus removal. The research results show that starch as a carbon source could more effectively promote the biological denitrification of the MPR system under the experimental operating conditions. Due to the slow degradation of starch, the carbon source requirement for denitrification was ensured during the operation cycle, so that the system had a better denitrification effect.

\section{Acknowledgments}

National Natural Science Foundation of China (51878067), High-Tech Division of Jilin Province Development and Reform Commission-Industrial Technology Research and Development (2019C056-4), Jilin Province Science and Technology Development Plan Project (20180201020SF, 20200201030JC).

\section{References}

1. Ai, S. , Dong, S. , Nie, Z. , Wang, F. , Sun, X. , Du, L. , Zhu, S. , Bian. D. Pilot study on urban sewage treatment with micro-pressure double-cycle reactor. Desalin. water Treat. , 215, 10-22, (2021).

2. Nie, Z., Huo, M. , Wang, F. , Ai, S. , Sun, X. , Zhu, S. , Li, Q. , Bian, D. Pilot study on urban sewage treatment with micro pressure swirl reactor. Bioresour. Technol. , 320, 124305, (2020).

3. Akunna J.C., Bizeau C. , Moletta R. Nitrate and nitrite reductions with anaerobic sludge using various carbon sources: Glucose, glycerol, acetic acid, lactic acid and methanol. Pergamon, 27, 8, (1993).

4. Huang, X. , Dong, W. , Wang H., Jiang S. Biological nutrient removal and molecular biological characteristics in an anaerobic-multistage anaerobic/oxic (A-MAO) process to treat municipal wastewater. Bioresour. Technol. , 241, 969-978, (2017).

5. Ai, S. , Dong, S. , Nie, Z. , Zhu, S. , Ren, Q. , Bian, D. Study on Aeration Optimization and Sewage Treatment Efficiency of a Novel Micro-Pressure Swirl Reactor (MPSR). Water, 12, 3, (2020).

6. Bian, D. , Nie, Z. , Wang, F. , Ai, S. , Zhu, S. , Guo, H. Micro-pressure swirl reactor (MPSR) for efficient COD and nitrogen removal of highconcentration wastewater. Water Sci. Technol., 82, 9, (2020).

7. Bian D. , Zhou D. , Huo M. ,Ren Q. ,Tian X. , Wan L., Zhu S., Ai S. Improving oxygen dissolution and distribution in a bioreactor with enhanced simultaneous COD and nitrogen removal by simply introducing micro-pressure and swirl. Appl. Microbiol. Biot. , 99, 20, (2015).

8. APHA. Standard methods for the examination of water and wastewater 22nd ed. Washington D.C.: American Public Health Association, American Water Works Association, and Water Environment Federation (2007).

9. Wei Y., Wang A. , Liao S. Effect of different carbon sources on microbial community structure and composition of ex-situ biofloc formation. Aquaculture, 515, (2020). 